\title{
Percepción de la competencia mediática y la formación en maestros chilenos
}

\author{
Perception of media literacy and training \\ in teachers from Chile
}

\author{
Pablo Maraver-López ${ }^{1}$ \\ pablomaraverlopez@gmail.com \\ Mari-Carmen Caldeiro-Pedreira ${ }^{2}$ \\ mariccaldeiro@gmail.com \\ Sandra Pérez-Lisboa ${ }^{3}$ \\ sandra.perez@upla.cl
}

\section{Resumen}

El presente trabajo analiza la realidad educativa de la zona de Los Andes respecto a los conocimientos tecnológicos que los maestros poseen en el ámbito de las nuevas tecnologías (TIC), también busca conocer los recursos con los que cuentan en el aula y el uso que realizan de los mismos. En el estudio se ha utilizado una metodología analítica y cuasi experimental a través de varias encuestas (pretest y postest). Los datos obtenidos pretenden justificar el uso de las TIC en las escuelas y el conocimiento que los maestros participantes poseen. Además de ello, focaliza la atención el peso que las TIC tienen en el currículo de educación en Chile y los programas y estrategias pedagógicas existentes en el país.

1 Doctor en Ciencias de la Educación. Profesor en el Departamento de Psicología social, evolutiva y de la educación de la Universidad de Huelva (España). Miembro del Grupo de Investigación Ágora HUM 648 y miembro de la Red Internacional Alfamed. Orcid: 0000-0003-2457-0887.

2 Doctora en Comunicación y Educación. Profesora del departamento de Psicología y Pedagogía de la Universidad Pública de Navarra (España). Profesora en diferentes universidades de España y Latinoamérica (Chile y Ecuador). Miembro del Consejo Técnico y del Consejo de Revisores (Advisory Board) de la Revista Científica de Comunicación y Educación "Comunicar". Académica a tiempo completo y coordinadora del Área de Investigación en el Campus de San Felipe de la Universidad de Playa Ancha (Chile). PhD en la Universidad Técnica del Norte (Ibarra, Ecuador). Investigadora en el Center for Higher Education Studies (República Checa). Orcid: 0000-0003-0160-3682.

3 Magíster en Pedagogía y Gestión Universitaria, Universidad Metropolitana de Ciencias de la Educación. Educadora de Párvulos, Pontificia Universidad Católica de Chile; Psicopedagoga. Docente del Departamento Disciplinario de Educación y Pedagogía, Universidad de Playa Ancha, Campus San Felipe. Orcid: 0000-0002- 0389-7242. 


\title{
Palabras clave
}

Alfabetización mediática, competencia, currículo educativo, formación, maestros, Chile.

Forma sugerida de citar: Maraver-López, Pablo, Caldeiro-Pedreira, Mari-Carmen, \& PérezLisboa, Sandra (2017). Percepción de la competencia mediática y la formación en maestros chilenos. Univeristas, XV(27), pp. 211-230.

\begin{abstract}
This paper analyzes the educational reality of Los Andes area with respect to the technological knowledge that teachers have in the field of new technologies (ICT), it also seeks to know the resources they have in the classroom and the use they make of them. In the study an analytical and quasi-experimental methodology has been used through several surveys (pretest and postest). The data obtained are intended to justify the use of ICT in schools and the knowledge that the participating teachers possess. In addition, attention is focused on the importance of ICTs in the education curriculum in Chile and the pedagogical programs and strategies that exist in Chile.
\end{abstract}

Keywords

Media literacy, skills, curriculum, training, teachers, Chile.

\section{Introducción y estado de la cuestión}

Hoy en día, la sociedad digital a la que se han referido autores como Terceiro (1996) o Tornero (2005), los nativos e inmigrantes digitales o la alfabetización digital y mediática son términos relativamente comunes. Así, la educación en sus diferentes niveles e independientemente del país al que nos refiramos, debe hacerse eco de ello. El ecosistema tecnológico circundante demanda un giro irremediable en el ámbito educativo, una modificación que ha de realizarse a nivel mundial en los distintos niveles educativos. Una afirmación que mantienen, entre otros, López, Opertti y Vargas (2017) en el informe sobre adolescentes y jóvenes en realidades cambiantes.

De la realidad actual se desprende la imperante necesidad de realizar innovaciones a gran escala, mejoras que justifican el interés de organizaciones de carácter mundial como la UNESCO. Organismos que focalizan la aten- 
ción en mejorar y transformar los sistemas, un hecho que preocupa a la administración de los diferentes países y a los diversos gobiernos que intentan dotar de herramientas tecnológicas a la mayor parte de las instituciones y centros educativos. En este sentido la Organización de Naciones Unidas (ONU) examina qué funciones pueden cumplir las TIC en la concepción de las políticas educativas atribuyéndole a la UNESCO el desempeño de una función normativa e informativa justificada por el acopio de datos y ejemplos sobre el uso de las TIC en el ámbito educativo. Además de ello pretende diseñar y elaborar diversos informes que muestran la información al respecto.

En este contexto cambiante, de renovación normativa, social y política se desarrolla la investigación que presentamos, un análisis de la realidad mediática actual que se produce en la denominada "sociedad líquida" (Bauman, 2000) donde todo cambia y pocas cosas permanecen, una sociedad en la que impera la obsolescencia programada, tanto de herramientas como de contenidos. En este espacio donde la presencia de los medios es rotunda (González-Fernández, Salcines-Talledo y Maraver-López, 2016), la información y los contenidos audiovisuales poseen un valor perecedero que puede atribuírsele a la multiplicidad de pantallas, la interactividad o la virtualidad. Aspectos todos ellos que impiden que se obvie la realidad y se oponen al continuo uso en las aulas de herramientas y estrategias didácticas propias de momentos anteriores donde imperaban pedagogías pasadas. Más allá de la visión de apocalípticos e integrados, en la era de la interactividad puede afirmarse con rotundidad que la perspectiva de unos y otros ha sido superada tanto por la tecnología como por los propios principios; en este sentido hoy en día existen diferentes estudios como los realizados por (RamírezGarcía, Renés-Arellano, Aguaded, 2016) que muestran la realidad en las aulas y justifican la necesidad de inclusión de nuevos proyectos centrados en el desarrollo de la competencia mediática por parte del alumnado. Para ello se apuesta por la formación continua del profesorado como indican Caldeiro y Aguaded (2012). Una formación que la UNESCO en su web identifica con el avance y la calidad docente que trasciende el marco teórico y se apoya en estándares tecnológicos referidos no solo a esta dimensión sino también a la producción reflexiva y crítica de contenidos. Especialmente hoy en día el profesorado ha de ser capaz de ayudar a los estudiantes para que trabajen, resuelvan problemas y desarrollen un aprendizaje creativo a través de las TIC. Para ello la UNESCO establece en su web una categorización 
en niveles que determina el grado de desarrollo y alcance de la competencia digital docente.

-En primer lugar hace referencia al aprendizaje de los elementos básicos de la tecnología, que permite el uso de las TIC por parte de los estudiantes y favorece el aprendizaje activo.

-El segundo nivel se centra en la profundización del conocimiento, que permite que los estudiantes adquieran conocimientos más avanzados de las asignaturas escolares y los apliquen a problemas complejos de la vida real.

-El tercer nivel guarda relación con el desarrollo de la capacidad de creación de nuevos conocimientos que contribuyen a la forja de sociedades armoniosas.

En cuanto al alcance de conocimientos, cabe destacar que apuesta por la alfabetización y el aprendizaje permanente adaptado a las necesidades de cada persona, independientemente de su situación o procedencia. En este sentido, centra la atención el aprendizaje permanente que englobe toda la actividad de adquisición de conocimientos, ya sean de carácter formal o informal, con el fin de mejorar las habilidades y las competencias, exigiendo un cambio de modelo que ponga énfasis en el aprendizaje, frente a la enseñanza y la capacitación (UNESCO, 2014) de manera que se promueva un cambio en los valores y actitudes (Quendler y Lamb, 2016).

Esta situación no es exclusiva del continente europeo y atiende, como señala la UNESCO (2016) en el apartado dedicado a buenas prácticas, a "las experiencias del Instituto Nacional de Educación Abierta de la India o los programas de RVA de Chile, México y Brasil". A estos ejemplos se suma el de Colombia donde se están desarrollando iniciativas que favorecen el alcance de la competencia mediática en la ciudadanía y de forma específica entre el alumnado y el profesorado (Sandoval et al., 2016).

Una realidad que no solo se hace extensible a otros países como Brasil, Ecuador o Chile sino que además, está presente en las políticas educativas que hacen referencia al uso de las TIC y su presencia en los planes de estudio. Una presencia que al igual que en el caso de España figura de forma tímida en el currículo donde se incluyen contenidos transversales o algunos específicos vinculados a la dimensión de la tecnología más que a las de análisis y producción de contenidos. 


\section{Alfabetización digital y mediática}

La realidad social circundante ha planteado la necesidad de que se asista al desarrollo de nuevas formas de aprender acorde a la existencia de nuevos medios y herramientas digitales. A lo largo de las últimas décadas del siglo XX diferentes organismos preconizaban la necesidad de preparar para convivir en un mundo dominado por las imágenes y los sonidos. Entonces ya se preveía el valor y el carácter de poder de los mismos si bien la presencia de los medios no poseía un carácter general ni se había extendido al nivel actual. Con el paso de los años la situación ha alcanzado límites insospechados, hoy en día la tecnología se ha convertido en un marco de referencia no solo comunicativo sino también de enseñanza y de aprendizaje.

En este sentido la alfabetización ha perdido el valor inicial que hacía referencia al aprendizaje de estrategias lecto-escritoras y ha alcanzado una dimensión digital connatural a la era mediática donde imperan las herramientas y medios tecnológicos que transmiten contenidos al instante. En este contexto la alfabetización digital ya no representa una opción sino que se ha convertido en una necesidad que es posible explicar atendiendo a una serie de criterios como: el funcionamiento de los motores de búsqueda y selección de la información que se difunde de manera desmesurada hoy en día, la gestión de la información, la privacidad o los derechos y libertades que se derivan de la emisión y la recepción de contenidos. En esta línea la alfabetización digital no consiste únicamente en "enseñar a utilizar el ordenador y distintas aplicaciones informáticas, sino que debe ofrecer los elementos básicos para la comprensión y dominio del lenguaje en el que están codificados los programas" (Levis, 2006, p. 78). La tecnología y su implantación general en el ecosistema actual demanda sujetos preparados, capaces no solo de decodificar adecuadamente sino de discernir y saber buscar información correctamente (Badwen, 2002). Esta idea discurre de forma paralela a los principios que se desprenden de la política europea que focaliza el interés en la formación del profesorado como estrategia básica para fortalecer la mejora de la calidad educativa.

Si nos referimos al contexto europeo, la formación se considera obligatoria en 28 sistemas educativos europeos siendo indispensable para la promoción en buena parte de ellos. Pese a que los docentes están preparados en sus materias, consideran que requieren formación en métodos didácticos, es decir, en el diseño de materiales adaptados a las necesidades más recientes. Por ende, esta idea enlaza de forma directa con la de alfabetización mediá- 
tica que propugnaba el CML (2003) al referirse al conjunto de herramientas necesarias para el alfabetismo en medios. Asimismo el CML, cree fundamental conocer: quién es el creador del mensaje, qué técnicas creativas se usan para llamar la atención, qué formas o maneras de comportamiento experimenta la audiencia de un mensaje, qué valores incorporan y por qué se envían. Por ello, define el proceso de alfabetismo en medios como el conjunto de habilidades que capacitan para acceder a los mensajes, analizarlos, evaluarlos y crearlos, todo ello de forma crítica y reflexiva. Una idea que se ha complementado y propagado a lo largo de la última década de tal forma que hoy en día, en diferentes países no solo del contexto europeo sino también del latinoamericano, contamos con experiencias en alfabetización que inciden en la formación del profesorado de niveles iniciales (Unesco, 2014b). Diferentes modos de alfabetizarse que inciden, en el desarrollo de "pedagogías emergentes" (Pérez-Lisboa y Caldeiro, 2017), modos de aprender y enseñar que promueven el alcance de la "competencia crítica" (Caldeiro y Aguaded, 2015) con base en el aprendizaje para todos (Unesco, 2016). Criterios que a su vez deben ser evaluados con el fin de valorar el nivel de consecución de los objetivos y de estandarizarlos; en esta línea destacan estudios como el dirigido por Pérez-Tornero (2009) que si bien está referido al ámbito europeo, podría utilizarse de modelo en otros contextos dado que busca facilitar el análisis y los criterios apropiados para la evaluación de los niveles de alfabetización mediática teniendo en cuenta el conjunto de políticas que se desarrollan en este ámbito. De un modo similar en países como Chile se han desarrollado programas de formación docente (Bitar, 2011) inspirados en diversas investigaciones que han salido a la luz a lo largo de la primera década del actual siglo y describen los estándares TIC para la formación inicial docente (Unesco, 2008). Iniciativas cuyo valor resulta significativo y al mismo tiempo sirven para analizar las diferencias y similitudes que pueden establecerse a nivel internacional.

Pese a todo, no existen proyectos concretos que puedan identificarse con la competencia mediática y su desarrollo, si bien se cuenta en este sentido con el esfuerzo de la Red Internacional Alfamed que se está desarrollando en diferentes países del contexto latinoamericano entre los que se encuentra Chile. Además de ello existen iniciativas como Mediabus que buscan conciliar posturas que vinculen la educación en medios y la escuela, principalmente rural. Proyectos que se llevan a cabo en el marco de convenios que la fundación que promueve la innovación e inclusión educativa establece con 
diversas universidades que imparten las carreras de pedagogía en sus diferentes ramas. Estas iniciativas pueden vincularse de forma indirecta con el desarrollo de la competencia mediática en tanto que favorecen la autonomía, la reflexión y la creatividad. Se trata de proyectos que apuestan por el alcance de la competencia crítica con base en la producción y análisis de contenidos audiovisuales por parte de los futuros docentes.

\section{La competencia mediática como forma de expresión crítica:}

más allá de la competencia audiovisual y la digital

La tecnología de la información, la práctica docente y los objetivos de la educación entendida esta última de forma genérica y no como la mera educación escolar, deben tender hacia el alcance de sujetos reflexivos, participativos y críticos, capaces de interactuar en la sociedad de la información, el conocimiento y la virtualidad. Para ello resulta imprescindible la inclusión de nuevas herramientas en al ámbito pedagógico, una inclusión a la que debe sumarse el alcance de niveles elevados en competencia mediática entendida como la habilidad conformada por la dimensión de: la tecnología, lenguajes, interacción, producción y difusión valores y estética. Dimensiones todas ellas que se configuran, siguiendo a (Ferrés y Piscitelli, 2012) en torno a dos grandes ámbitos: análisis y expresión y que conllevan el desarrollo de indicadores que pueden utilizarse para definir el nivel de producción de contenidos del receptor, también conocido como "prosumer" (SánchezCarrero y Contreras, 2012).

En este sentido la competencia mediática trasciende a la digital y audiovisual completándolas en tanto que hace hincapié no solo en el uso tecnológico y el manejo de las herramientas digitales ni tampoco en el análisis de contenidos sino que establece un conjunto de dimensiones que debe desarrollar un receptor activo que pertenece a la sociedad multipantalla (Ortiz, 2008) en la cual más allá del consumismo se busca el alcance y desarrollo de la actitud reflexiva y crítica que se opone a la proliferación de conductas perniciosas derivadas del incorrecto manejo de los dispositivos tecnológicos y de la lectura errónea de los contenidos audiovisuales. Además, en la actualidad impera la necesidad de empoderar a los usuarios de por ejemplo, las redes sociales que se han convertido en uno de los medios de comunicación más utilizados, especialmente entre el colectivo adolescente. En este sentido y según afirmaban (Tejedor y Pulido, 2012) conviene tener en cuen- 
ta los retos y riesgos de la red y la virtualidad. Hoy en día, además de leer la información constituye una necesidad perentoria su correcta decodificación y adecuada producción, especialmente en un momento en el cual se difunde de manera inmediata y en ocasiones irregular.

Por tanto resulta fundamental el desarrollo de la competencia mediática en cada una de sus dimensiones; asimismo constituye una necesidad imperiosa alfabetizar no solo a los menores sino a la población en general y de forma especial a los docentes y a los progenitores que pertenecen al grupo de los "visitantes digitales" (White y Le Cornu, 2011). En la sociedad móvil digital actual conviene que los "natitantes" (Fernández-García, Blasco y Caldeiro, 2016), es decir los nativos y los visitantes digitales, se interrelacionen tanto si conviven en un mismo espacio presencial como si es virtual. Independientemente del nivel de desarrollo y manejo de las tecnologías y de la capacidad de decodificar los contenidos audiovisuales "visitantes y residentes digitales" (White y Le Cornu, 2011) han de desarrollar el nivel óptimo de competencia mediática que les capacita para expresarse de forma crítica y autónoma y para desenvolverse en medio de superabundancia de información que tiende a la sobrecarga desmedida también denominada "infopolución" o "infoxicación" (Aguaded, 2014).

Para ello se propone la educación en medios también denominada "educomunicación" que aboga por la formación para los medios, una tarea que resulta compleja teniendo en cuenta que la competencia mediática no figura entre aquellas que componen el currículo. Si bien si puede vincularse de forma transversal e interdisciplinar en la práctica totalidad de asignaturas y programas formativos.

\section{La realidad chilena}

En las últimas décadas, las políticas educacionales que se han impulsado en Chile en busca de mejorar la calidad han permitido innovar y modernizar los aprendizajes en la sala de clases. En este contexto destaca la iniciada en el año 1992, con la creación del proyecto piloto Enlace que tiene como objetivo integrar las TIC en la educación para mejorar los aprendizajes. Por los resultados obtenidos, este proyecto se transforma en el año 2005 en el Programa Enlace, dependiente del Ministerio de Educación como Centro de Educación y Tecnología de Chile. Entre sus objetivos destaca la incorporación de ordenadores, software e Internet en las escuelas de todo el país. A nivel curricular, con la reforma Educacional del año 1998, se ha incorporado 
informática en Educación Media, para lograr desarrollar capacidades de manejo de software, y de búsqueda y selección de información, objetivos que coinciden con los del CML, anteriormente señalados. Más adelante, en el año 2001, se crea el portal educarchile.cl, con el objetivo de mejorar la calidad de la educación, brindando recursos, servicios y experiencias educativas para los docentes, estudiantes y familias. Al año siguiente, se implementa el programa de Tecnologías de Información y Comunicación Efectivas para Educación TIC EDU de FONDEF (Fondo de Fomento al Desarrollo Científico y Tecnológico). Este programa TIC EDU, tiene como objetivo contribuir a elevar la calidad de la educación mediante el desarrollo de productos o servicios TIC innovadores orientados a mejorar los procesos de aprendizaje. A finales de 2014 se presentan los resultados de la segunda aplicación nacional de Evaluación de Habilidades TIC para el Aprendizaje. Unos resultados que afirman que el 46,9\% de los estudiantes se encuentran en un nivel Inicial frente al 51,3\% de los estudiantes que alcanzan un nivel Intermedio y tan solo el 1,8\% obtiene el nivel Avanzado. Para fortalecer la Educación Pública, el actual gobierno de la Presidenta Michelle Bachelet creó otro programa llamado 'Me conecto para aprender', que permite facilitar ordenadores a todos los estudiantes de establecimientos municipales de $7^{\circ}$ año de educación básica. Además este programa incluye a lo largo de un año banda ancha móvil gratuita y diversos recursos educativos que los estudiantes tienen a su disposición por asignatura, con simuladores y programas de imágenes y audio para realizar sus tareas y trabajos investigando en diferentes sitios de la red. Este gobierno espera hacer llegar a los centros, entre los cuales ha incluido en 2016 a estudiantes adultos, un total de 300 mil ordenadores. La realidad refuerza, en el caso de Chile que existe una gran presencia de los nuevos dispositivos tecnológicos y una ligera y continua inclusión de los mismos en el ámbito académico.

Por tanto, descrito el contexto mediático actual y la presencia de estos contenidos en el ámbito educativo y en sus correspondientes políticas, es necesario perfilar de forma concreta los principales objetivos de la investigación que se presenta. El Objetivo general es analizar la percepción de la competencia mediática y la formación en maestros chilenos. Para ello, se plantean los siguientes objetivos específicos:

Objetivo 1: analizar la realidad educativa de la zona de Los Andes respecto a los conocimientos tecnológicos que el profesorado posee en el ámbito de las TIC. 
Objetivo 2: conocer los recursos con los que cuentan en el aula y el uso que realizan de los mismos. Objetivo 3: indagar sobre la importancia que el profesorado otorga a las TIC para la educación actual y analizar su percepción sobre las habilidades que creen tener y el conocimiento de los intereses y preferencias de sus estudiantes.

Objetivo 4: conocer las ventajas y limitaciones que el profesorado manifiesta respecto al uso de las herramientas tecnológicas en el aula.

Objetivo 5: analizar el impacto de un curso de formación sobre competencia mediática para el profesorado.

\section{Material y métodos}

Para cumplir con los objetivos propuestos, se ha utilizado una metodología analítica, en concreto, se trata de un estudio pre-post, que permite una recolección de datos clara, rigurosa y confiable. El tipo de investigación es de tipo cuasiexperimental que permitirá determinar el grado de relación o asociación no causal existente entre las variables del estudio.

\section{Procedimiento}

El presente estudio se llevó a cabo en el contexto educativo de la región de los Andes en Chile. La información que arrojan los datos referidos se ha extraído del análisis e impacto de un curso de formación ofrecido al profesorado en el cual se ha realizado una presentación general sobre el aprendizaje por competencias que se ha iniciado en el Informe DeSeCo (1998) y más concretamente sobre competencia mediática. Los datos fueron recogidos a través de dos cuestionarios elaborados ad hoc que pretenden analizar los conocimientos y competencias del profesorado frente a las TIC.

\section{Participantes}

En este estudio han participado un total de 31 maestros y maestras de una escuela de Los Andes (Chile). Se trata de una institución que dispone de ordenadores y que se encuentra inmersa en el programa de digitalización del gobierno si bien, como indican los participantes, carecen de formación adecuada para la inserción de las herramientas en el quehacer diario. 


\section{Instrumentos}

Para esta investigación se han empleado dos instrumentos: un cuestionario inicial sobre los conocimientos y percepciones que los docentes de infantil y primaria poseen acerca de las TIC en la educación y un segundo cuestionario de valoración de una actividad formativa sobre las TIC en la que el profesorado ha participado. Es decir, al principio el profesorado ha respondido a un cuestionario inicial y al finalizar la formación han cumplimentado el cuestionario final.

\section{Análisis y resultados}

Los resultados que se exponen a continuación siguen el mismo orden que los objetivos de la investigación.

Objetivo 1: Resultados sobre los conocimientos tecnológicos que el profesorado posee en el ámbito de las TIC.

Para dar respuesta a este objetivo, se realizaron varias preguntas al profesorado respecto al conocimiento que poseen sobre el término alfabetización, el término competencia mediática y la necesidad de formación del docente para el uso de las TIC en el aula (Figura 1). 
Figura 1

Conocimientos tecnológicos del profesorado en el ámbito TIC

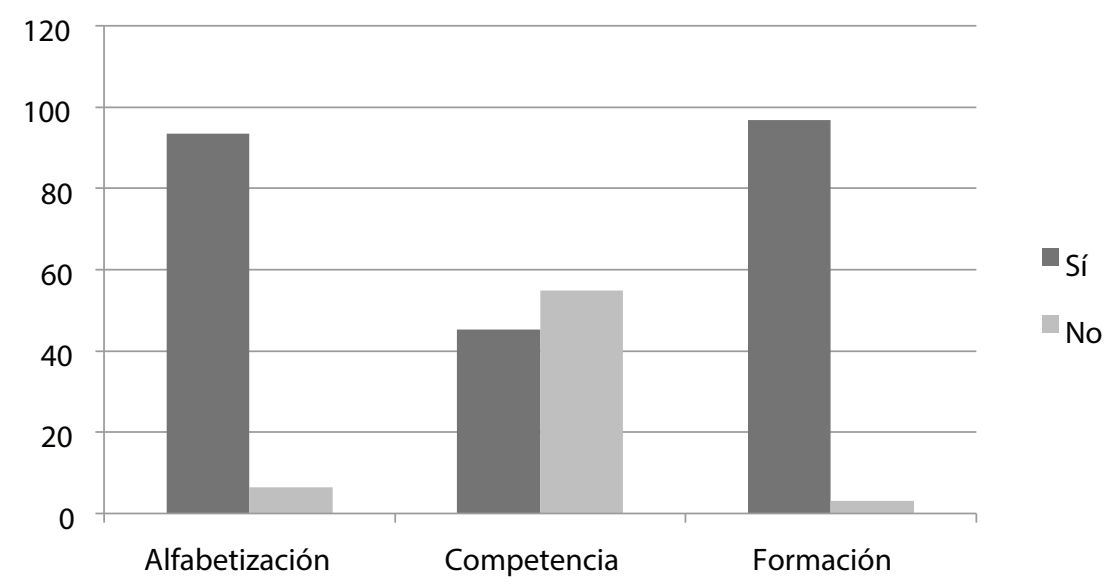

Fuente: Elaboración propia

En esta primera encuesta, previa a la actividad formativa, el 93,5\% de profesorado encuestado afirma conocer el término alfabetización. Al mismo tiempo, el 45,2\% afirma conocer el término competencia mediática, frente al 54,8\% que aún no lo conoce. Por otra parte, el 96,8\% de las personas encuestadas considera necesaria la formación del docente para el uso de las TIC en el aula.

Objetivo 2: Resultados sobre los recursos con los que cuentan en el aula y el uso que realizan de los mismos.

El 100\% del profesorado encuestado confirma que su centro cuenta con herramientas tecnológicas.

A pesar de ello, el 77,4\% utiliza herramientas tecnológicas en sus clases frente a un 22,6\% que no las utiliza. La frecuencia de uso de las personas que sí utilizan TIC en sus clases se puede ver en la Figura 2. 


\section{Figura 2 \\ Frecuencia de uso de las TIC por parte del profesorado}

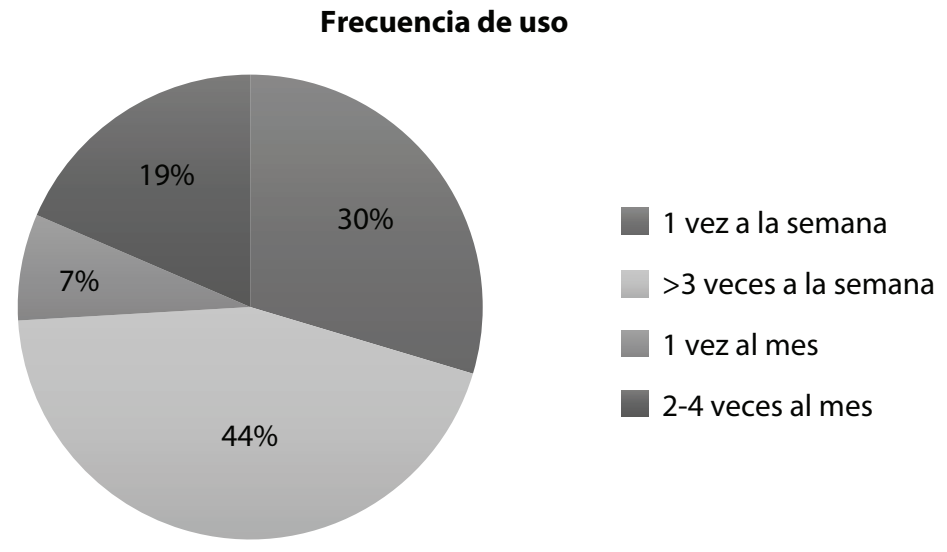

Fuente: Elaboración propia

Tal y como se observa en la Figura 2, un 29,6\% utiliza las TIC una vez a la semana; El 44,4\% más de tres veces a la semana; El 7,4\% la utilizan una vez al mes; Y el 18,5\% hace uso de las TIC más de una vez al menos y menos de 4 veces.

Objetivo 3: Resultados sobre la importancia que el profesorado otorga a las Tic para la educación actual y analizar su percepción sobre las habilidades que creen tener y el conocimiento de los intereses y preferencias de sus estudiantes.

En la encuesta, el 97\% de profesores se ha mostrado totalmente de acuerdo con esta afirmación "Las TIC son necesarias en la educación hoy en día".

Además, el 94\% ha respondido que conoce las necesidades del estudiante de hoy en día.

Otra cuestión aborda "Cuáles son las inquietudes preferentes del alumnado". Gracias a las respuestas abiertas obtenidas podemos observar que el profesorado detecta que los intereses e inquietudes de su alumnado son: 
- Aprender de un modo significativo, información de interés para el alumnado, a través del uso de las TIC e innovar.

- Buscar información, jugar en red, comunicarse a través de redes sociales.

- Llevar a cabo clases interactivas, los estudiantes quieren hacer y participar, no quieren que un profesor hable durante toda la clase.

- Comunicarse con los pares.

- Buscar información y crear sus trabajos propios.

- Configurar y desarrollar tareas.

- Usar programas de interés para los estudiantes.

- Conectar la materia con las redes sociales.

- Jugar, investigar, manipular, aprender conceptos, navegar, chatear.

- Estar a la moda, ser parte de la sociedad.

- Estar actualizados en las redes sociales.

- Estar conectados al mundo y estudiar.

- Compartir conocimiento.

- Motivarse.

- Intereses sociales, sexuales y tecnológicos.

Objetivo 4: Resultados sobre las ventajas y limitaciones

que el profesorado manifiesta respecto al uso de las herramientas tecnológicas en el aula

A este respecto, el profesorado describe una serie de ventajas y limitaciones sobre el uso de las TIC en el aula (Tabla 1). 


\section{Tabla 1 \\ Ventajas y limitaciones del uso de las TIC en el aula}

\begin{tabular}{|c|c|}
\hline Las herramientas tecnológicas favorecen & $\begin{array}{l}\text { Las herramientas } \\
\text { tecnológicas dificultan }\end{array}$ \\
\hline "Aprendizajes significativos y lúdicos" & "Ante tantas opciones no saben que elegir" \\
\hline "Búsqueda de información rápida" & "Depende de las reglas que los padres tengan en sus casas" \\
\hline $\begin{array}{l}\text { "A los niños les gusta construir usando las TIC así que la clase } \\
\text { se vuelve significativa, mejora el clima dentro del aula" }\end{array}$ & $\begin{array}{l}\text { "No permite desarrollar comunicación o potenciar, } \\
\text { encasilla y coarta las respuestas" }\end{array}$ \\
\hline $\begin{array}{l}\text { "Ayudan a desarrollar competencias, expresar conocimientos, } \\
\text { habilidades, aprendizajes..." }\end{array}$ & $\begin{array}{l}\text { "Solo quieren usar las redes sociales y no para } \\
\text { aprender, no saben resumir o extraer información" }\end{array}$ \\
\hline "Facilita el aprendizaje del conocimiento" & "Afecta a la comunicación de personas más aisladas" \\
\hline $\begin{array}{l}\text { "Favorecen, motivan para aprender, ayudan a los profesores } \\
\text { que lo usan didácticamente" }\end{array}$ & "Entorpece" \\
\hline $\begin{array}{l}\text { "Facilita los aprendizajes especialmente en mates, el medio } \\
\text { audiovisual es motivador para desarrollar y estimular los } \\
\text { sentidos" }\end{array}$ & "La información no siempre es fidedigna" \\
\hline $\begin{array}{l}\text { "Facilita para poder exponer los contenidos adecuados, } \\
\text { favorece el conocimiento y la investigación" }\end{array}$ & "Es un arma de doble filo" \\
\hline $\begin{array}{l}\text { "Facilitan y mejoran la calidad de los aprendizajes, mayor } \\
\text { interés por aprender a través de las TIC" }\end{array}$ & $\begin{array}{l}\text { "Dificultan si hay mal uso en el aula y no presentan } \\
\text { atención" }\end{array}$ \\
\hline "Facilitan porque es interactiva y concreta" & $\begin{array}{l}\text { "Dificultan por el aumento de obesidad y falta de } \\
\text { actividad física" }\end{array}$ \\
\hline "Facilitan pues entregan información inmediata y complementa" & "Dificultan cuando el docente no maneja las TIC" \\
\hline \multicolumn{2}{|l|}{$\begin{array}{l}\text { "Favorece la atención de los niños, más conocimiento de la } \\
\text { era moderna" }\end{array}$} \\
\hline \multicolumn{2}{|l|}{ "Favorece un fácil acceso a la información" } \\
\hline \multicolumn{2}{|l|}{ "Facilitan el trabajo, obtener información pedagógica" } \\
\hline \multicolumn{2}{|l|}{$\begin{array}{l}\text { "Favorecen labor docente siendo un apoyo de interés para } \\
\text { alumnos, clases motivadoras y dinámicas" }\end{array}$} \\
\hline \multicolumn{2}{|l|}{ "Favorecen para el desarrollo del futuro en la tecnología" } \\
\hline \multicolumn{2}{|l|}{ Favorecen porque son motivadoras e innovadoras" } \\
\hline \multicolumn{2}{|l|}{ Favorecen pues da herramientas e información para el aprendizaje" } \\
\hline \multicolumn{2}{|l|}{$\begin{array}{l}\text { "Favorecen pues se obtiene información al momento y es } \\
\text { llamativo para alumnos" }\end{array}$} \\
\hline \multicolumn{2}{|l|}{$\begin{array}{l}\text { "Favorecen si son bien usados, con material que facilite en } \\
\text { aprendizaje" }\end{array}$} \\
\hline $\begin{array}{l}\text { "Favorecen al nivel de desarrollo e interés de los niños, } \\
\text { favorece aportan recursos y aprendizaje significativo" }\end{array}$ & \\
\hline
\end{tabular}




\begin{tabular}{|c|c|}
\hline Las herramientas tecnológicas favorecen & $\begin{array}{l}\text { Las herramientas } \\
\text { tecnológicas dificultan }\end{array}$ \\
\hline "Favorecen ya que les servirá en el futuro" & \\
\hline $\begin{array}{l}\text { "Favorecen ya que muestran un mundo de posibilidades por } \\
\text { descubrir }\end{array}$ & \\
\hline $\begin{array}{l}\text { "Favorecen, lo hacen más motivante y participativo, más } \\
\text { contextualizado" }\end{array}$ & \\
\hline
\end{tabular}

Fuente: Elaboración propia

De las opciones que refleja la Tabla 1 se deduce que la muestra participante considera que las herramientas tecnológicas y el uso de las TIC en el aula acarrean más ventajas que inconvenientes y subrayan entre los aspectos positivos la búsqueda de información que es una de las dimensiones que destaca en el Marco de competencia docente del Intef (2017).

\section{Objetivo 5: Resultados sobre el impacto de un curso de formación del profesorado}

Abordando este último objetivo, el 90,3\% de los maestros y maestras respondieron que la información recibida en la actividad formativa le ha interesado mucho.

Además, un 87,1\% consideró que la información trabajada en la actividad formativa le ayudó mucho a clarificar conceptos. Por su parte, el 93,5\% se mostraron interesados en conocer más información al respecto de esta temática. En relación a los materiales utilizados para la actividad formativa, un $84 \%$ de las personas participantes manifestaron que sí le han resultado adecuados.

Finalmente, al comparar las puntuaciones obtenidas en el cuestionario previo a la actividad formativa, con el cuestionario final, se obtienen diferencias estadísticamente significativas $(p<0.05)$ ante la pregunta "Conoces el término alfabetización" $100 \%$, frente un porcentaje inferior del profesorado que afirmaba conocer el término alfabetización antes de la formación lo cual significa que, conforme se señala en esta investigación, resulta imprescindible la formación acorde a las nuevas necesidades. En respuesta a la pregunta "Conoces el término competencia mediática" 97\% afirma conocer el término competencia mediática frente al $45 \%$ que afirmaban que lo conocían antes de iniciar del taller. Una respuesta que confirma la importancia de la formación continua del profesorado y su efectividad. 


\section{Discusión y conclusiones}

La realidad tecnológica y la ingente cantidad de contenidos audiovisuales que fluyen a través de los canales hipermedia, certifican el necesario cambio pedagógico. En Chile, el compromiso gubernamental consistente en dotar de herramientas a los centros y la tímida inclusión de informática en el currículo resulta insuficiente para el desarrollo de la tarea docente. Los profesionales que han participado en el estudio señalan la necesidad de recibir formación y analizar pormenorizadamente estos aspectos.

Entre las limitaciones de este estudio cabe citar por un lado las dificultades de infraestructura referidas fundamentalmente a la conexión a Internet que ha dificultado el desarrollo del curso y a la duración de la capacitación que se ha desarrollado en una sola sesión. En este sentido, casi el 100\% del profesorado del centro señalaban que debería repetirse o al menos prolongarse más. Por otro lado, en cuanto a las limitaciones conceptuales destaca el escaso conocimiento de la mayoría de participantes quienes desconocían, en su mayoría, el término competencia mediática. Una limitación que puede relacionarse de forma directa con los aspectos a mejorar que han citado los participantes que apelaban a la falta de actividades concretas y la profundización en la temática.

Además, han señalado diversas propuestas ante la pregunta: "Qué aspectos mejorarías en el diseño de la actividad formativa", respuestas que apuntan, tanto a la necesidad de recibir formación y clases de carácter práctico donde pueda verse cómo aplicar los contenidos impartidos en el curso, así como al grado de profundización y la continuidad de los temas tratados.

En general, destaca el interés del profesorado por estar formado y por conocer más sobre alfabetización mediática y la necesidad de que se implementen propuestas en esta misma línea. Además de ello, se percibe un cierto desinterés por parte de la administración y el gobierno que, si bien ha dotado de herramientas a los centros educativos convirtiéndolos, como es el caso de la escuela a la que nos hemos referido, en centros TIC, no capacita al profesorado adecuadamente, según las necesidades detectadas. Por ende, iniciativas como la que hemos puesto en marcha, siguiendo el marco de las Recomendaciones sobre alfabetización dictadas por el Parlamento y la Comisión Europea (2009), y teniendo en cuenta que los medios ejercen una notable influencia sobre el receptor (Alvarado, 2012), deberían repetirse y ampliarse. Un deseo que reflejan en sus respuestas los participantes que si 
bien consideran en un $97 \%$ que el uso de las TIC es muy importante, afirman que carecen de las habilidades necesarias para implementarlas en su trabajo como docentes. Una respuesta que avala la baja frecuencia de uso que señalan tener sobre las citadas herramientas y que certifica los resultados que dan respuesta a los objetivos abordados en este estudio.

\section{Apoyos y agradecimientos}

Este trabajo está avalado por el Proyecto I+D+I, titulado "Competencias mediáticas de la ciudadanía en medios digitales emergentes (smartphones y tablets): practicas innovadoras y estrategias educomunicativas en contextos múltiples" con clave EDU2015-64015-C3-1-R (MINECO/FEDER), financiado por el Fondo Europeo de Desarrollo Regional (FEDER) y Ministerio de Economía y Competitividad de España.

\section{Bibliografía}

Aguaded, I. (2014). Desde la infoxicación al derecho a la comunicación [From Infoxication to the Right to Communicate]. Comunicar, 42, 07-08. https:// doi.org/10.3916/C42-2014-a1

Alvarado, J. (2012). Medios de comunicación y política exterior del estado. La prensa y el proceso de paz Ecuador-Perú: 1998. Universitas 16, 69-92. Recuperado de https://goo.gl/xY2DtD

Bauman, Z. (2000). Modernidad líquida. FCE: México http://goo.gl/SsvyKr

Bitar, S. (2011). Formación docente en Chile. CINDE: Chile. Recuperado de https:// goo.gl/gSPr8s

Caldeiro-Pedreira, M. C. \& Aguaded-Gómez, I. (2012). Autonomía mediática en docentes y discentes deeducación secundaria. Contribuciones del Centro de Formación y Recursos de Lugo. Revista Aularia, 1(2), 187-195. Recuperado de http://goo.gl/Ms0wIH

Caldeiro-Pedreira, M. C. \& Aguaded-Gómez, I. (2015). 'Estoy aprendiendo, no me molestes' la competencia mediática como forma de expresión crítica de nativos e inmigrantes digitales. Redes.com, 12. Recuperado de http:// goo.gl/2ORkf1

Celot, P. (Project Coordinator and editor), \& Pérez-Tornero, J. M. (Scientific Coordinator). (2009). Study on Assessment Criteria for Media Literacy Le- 
vels - A comprehensive view of the concept of media literacy and an Understanding of how media literacy level in Europe Should Be Assessed. Brussels: European Commission. Recuperado de http://goo.gl/rnXfa8

DeSeCo (1998). La definición y selección de competencias clave. Recuperado de https://goo.gl/fIi9Pq

Fernández-García, N; Blasco-Duatis, M. \& Caldeiro-Pedreira, M. (2016). Communication and Education by Transmedia. Report on ICT skills in four secondary schools in Europe. Cuadernos Artesanos de Comunicación, 108 - English Version. La Laguna (Tenerife): Latina. Recuperado de http:// goo.gl/fl9mrK

Ferrés, J. \& Piscitelli, A. (2012). La competencia mediática: propuesta articulada de dimensiones e indicadores. Comunicar, 38, 75-82. doi.org/10.3916/ C38-2012-02-08

González-Fernández, N.; Salcines-Talledo, I. \& Maraver-López, P. (2016) Spanish parents' perception of family media literacy. Cultura y educación, 28, 468-199. http://dx.doi.org/10.1080/11356405.2016.1196898

INTEF (2017). Marco Común de Competencia Digital Docente. Recuperado de https://goo.gl/OQkj6R

Levis, D. (2006). Alfabetos y saberes: la alfabetización digital [Literates and knowledge: the digital literacy]. Comunicar, 26, 78-82

López, N; Opertti, L. \& Vargas, C. (coord.) (2017). Adolescentes y jóvenes en realidades cambiantes. Notas para repensar la educación secundaria en América Latina. UNESCO: Francia. Recuperado de https://goo.gl/6PPcqC

Ortiz, M.Á. (2008). Educar la mirada en la 'sociedad multipantalla' [To teach the look in a multi-screen society]. Comunicar, 31, 10-13. https://doi. org/10.3916/c31-2008-01-001

Pérez-Tornero, J.M. (2005). El futuro de la sociedad digital y los nuevos valores de la educación en medios [The future of the digital society and values in media education]. Comunicar, 25, 247-258

Pérez-Lisboa, S. \& Caldeiro-Pedreira, M. C (2017). Aula didáctica digital: realidad aumentada y pizarra digital interactiva. Revista Didáctica, Innovación y Multimedia, 35. Recuperado de https://goo.gl/1R5mn4

Quendler, E. \& Lamb, M. (2016). Learning as a lifelong process - meeting the challenges of the changing employability landscape: competences, skills and knowledge for sustainable development. International Journal of Continuing Engineering Education and Life Long Learning, 26(3), 273-293. DOI http://dx.doi.org/10.1504/IJCEELL.2016.078447. 
Ramírez-García, A., Renés-Arellano, P., Aguaded Gómez, J. (2016). La competencia mediática en los criterios de evaluación del currículo de Educación Primaria. Aula Abierta. 44, 2, 55-62, DOI: 10.1016/j.aula.2015.08.002

Sánchez-Carrero, J. y Contreras-Pulido, P. (2012). De cara al prosumidor: Producción y consumo empoderando a la ciudadanía 3.0. Icono 14, 10 (3), 6284. Recuperado de https://goo.gl/ge7Ija

Sandoval, Y.; Manrique, J.; Arenas, A.; Martínez, M. C; Hernández, M. \& Serna, A. (2016). Los jóvenes y la competencia mediática.Valle del Cauca-Colombia. Editorial USC:Colombia

Terceiro, J. (1996). Sociedad digital: del homo sapiens al homo digitalis. Madrid: Alianza eEditorial.

UNESCO (2008). Estándares TIC para la formación inicial docente: una propuesta en el contexto chileno. Chile: Gráfica LOM. Recuperado de https://goo. $\mathrm{gl} / \mathrm{t} 0 \mathrm{HG} 3 \mathrm{G}$

UNESCO (2014). UNESCO Education Strategy 2014-2021. París: UNESCO. Recuperado de: https://goo.gl/Cbr2lg.

UNESCO (2014b). Informe sobre tendencias sociales y educativas en América Latina 2014. Recuperado de https://goo.gl/kPDhct

UNESCO (2016). Tecnología digital al servicio de la calidad educativa. Una propuesta de cambio centrada en el aprendizaje para todos. Unesco Santiago.

White, D. \& Le Cornu, A. (2011). Visitors and Residents: A new typology for online engagement. First Monday, 9(16). Recuperado de http://dx.doi. org/10.5210/fm.v16i9.3171

Fecha de recepción: 20/05/2017; fecha de aceptación: 18/08/2017; fecha de publicación: 01/09/2017 